Subscriber access provided by FLORIDA INTL UNIV

Article

\title{
Hydrocracking of long paraffins over Pt-Pd/WO3- ZrO2 in the presence of sulfur and aromatic impurities
}

Mariana Busto, Javier Mario Grau, Jorge H. Sepulveda, Oksana M. Tsendra, and Carlos Román Vera

Energy Fuels, Just Accepted Manuscript • DOI: 10.1021/ef401138v • Publication Date (Web): 15 Oct 2013

Downloaded from http://pubs.acs.org on October 20, 2013

\section{Just Accepted}

"Just Accepted" manuscripts have been peer-reviewed and accepted for publication. They are posted online prior to technical editing, formatting for publication and author proofing. The American Chemical Society provides "Just Accepted" as a free service to the research community to expedite the dissemination of scientific material as soon as possible after acceptance. "Just Accepted" manuscripts appear in full in PDF format accompanied by an HTML abstract. "Just Accepted" manuscripts have been fully peer reviewed, but should not be considered the official version of record. They are accessible to all readers and citable by the Digital Object Identifier (DOI®). "Just Accepted" is an optional service offered to authors. Therefore, the "Just Accepted" Web site may not include all articles that will be published in the journal. After a manuscript is technically edited and formatted, it will be removed from the "Just Accepted" Web site and published as an ASAP article. Note that technical editing may introduce minor changes to the manuscript text and/or graphics which could affect content, and all legal disclaimers and ethical guidelines that apply to the journal pertain. ACS cannot be held responsible for errors or consequences arising from the use of information contained in these "Just Accepted" manuscripts. 


\title{
Hydrocracking of long paraffins over $\mathrm{Pt}-\mathrm{Pd} / \mathrm{WO}_{3}-\mathrm{ZrO}_{2}$ in the presence of sulfur and aromatic impurities
}

\author{
Mariana Busto ${ }^{\dagger}$, Javier M. Grau ${ }^{\dagger}$, Jorge H. Sepulveda ${ }^{\dagger}$, Oksana M. Tsendra ${ }^{\ddagger}$ and Carlos R. \\ Vera $^{\dagger}$ \\ ${ }^{\dagger}$ Instituto de Investigaciones en Catálisis y Petroquímica (INCAPE), Facultad de Ingeniería Química, \\ Universidad Nacional del Litoral, Santiago del Estero 2654, 3000 Santa Fe, Argentina \\ $\ddagger$ Chuiko Institute of Surface Chemistry, National Academy of Sciences, 17 General Maumov Street, \\ Kiev 03164, Ukraine
}

\begin{abstract}
The hydrocracking of long paraffins in the presence of sulfur and aromatic impurities using $\mathrm{Pt}-\mathrm{Pd} / \mathrm{WO}_{3}-\mathrm{ZrO}_{2}$ was assessed. The catalysts were tested for $\mathrm{n}$-hexadecane hydrocraking in the presence and absence of several poisons, benzothiophene, quinolein, carbon disulfide, benzene and naphthalene. At small impurity levels aromatics are beneficial for the hydrocracking of long paraffins because they increase the liquid yield and reduce the cracking to light gases. Sulfur compounds were strong poisons of the activity. Benzothiophene was the strongest, producing the highest decline in activity and being more strongly chemisorbed than basic quinolein. Sulfur poisoning drastically affected the hydrocracking activity indicating that acid isomerization-cracking on $\mathrm{WO}_{3}-\mathrm{ZrO}_{2}$ follows a bifunctional mechanism with big influence of the metal function. Incorporation of $\mathrm{Pd}$ to $\mathrm{Pt} / \mathrm{WO}_{3}-\mathrm{ZrO}_{2}$ reduced the sulfur poisoning, $\mathrm{Pt}-\mathrm{Pd}(3: 1) / \mathrm{WO}_{3}-\mathrm{ZrO}_{2}$ being the best catalyst for stable hydrocracking of long paraffins in the presence of sulfur. This catalyst retained most of the activity of the $\mathrm{Pt} / \mathrm{WO}_{3}-\mathrm{ZrO}_{2}$ parent material while being less affected by sulfur.
\end{abstract}




\section{TOC Graphical Abstract}

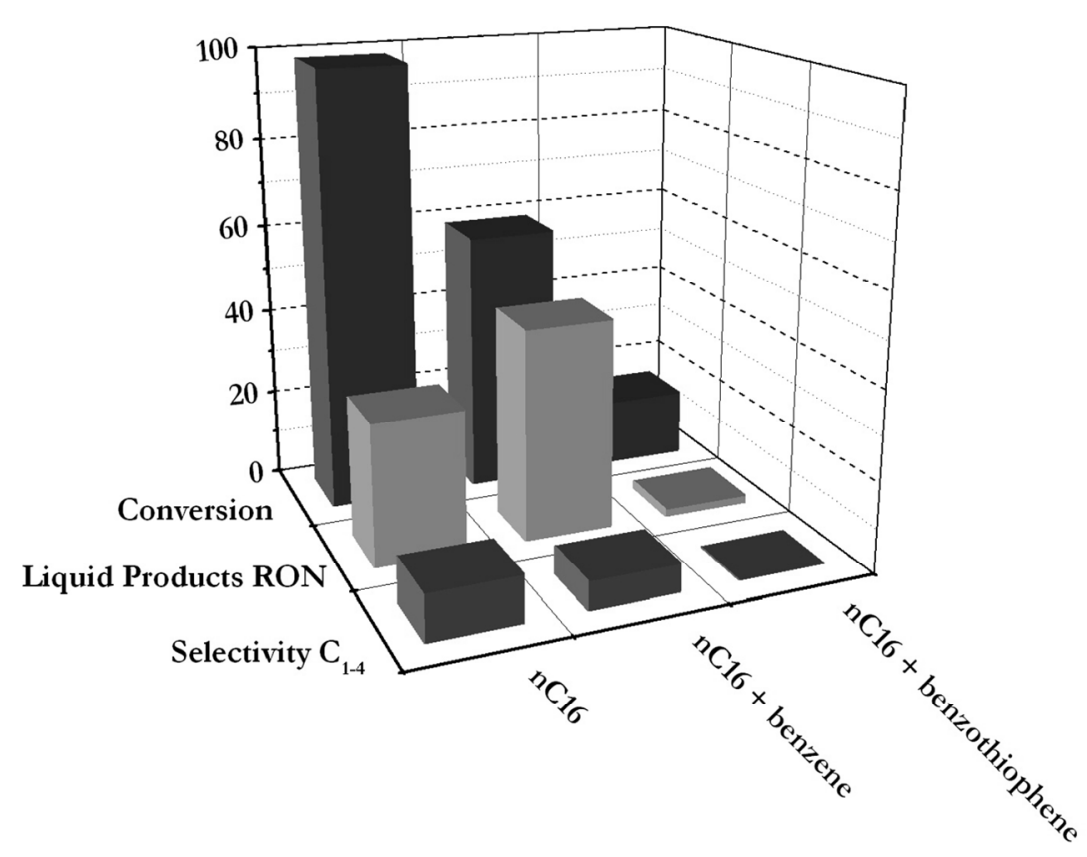

Reaction of $n$-hexadecane $\left(n-C_{16}\right)$ doped (4\% vol/vol) with benzene $(B z)$ and benzothiophene (Btf). Reaction conditions: $225^{\circ} \mathrm{C}, 20 \mathrm{~atm}, \mathrm{H}_{2} / \mathrm{HC}=10, \mathrm{WHSV}=18.4 \mathrm{~h}^{-1}$, time-on-stream $=1 \mathrm{~h}$.

Keywords

Tungstated zirconia; Palladium; Platinum ; Benzothiophene; Sulfur

\section{INTRODUCTION}

The main three problems faced by modem refiners can be described as: (i) the change in the classical demand pattern of light cuts (gasolines), middle distillates (kerosene, diesel, lubes) and heavy cuts, with a shift towards the production of more gasolines and middle distillates; (ii) the need to process increasingly heavier cuts, with a higher content of polyaromatics, 
resins and asphalthenes; (iii) stricter environmental regulations that limit the fuel content of some noxious compounds, like sulfur and aromatics. The refiners' solution has been an increased use of FCC and hydrocracking units to augment the production of lighter cuts and an upgrade of hydrotreating facilities to process more difficult feeds to cleaner end products.

In the case of hydrocracking mostly used feedstocks are atmospheric and vacuum gasoils. An alternative and more rare feedstock are the heavy paraffins. They have lately attracted some industrial and scientific interest because of their potential contribution to the gasoline pool. One problem with these waxy feeds is the process conditions found in most hydrocrackers that favor the cracking and branching of the paraffins. A high degree of branching is very bad for the quality of the diesel product. However it is not easy to eliminate branching in these units without inhibiting cracking at the same time, since both reactions are favored by temperature and acid catalysis. For these reason many researchers have focused their attention on the conversion of waxy feedstocks into high octane isomerizate gasolines. In this sense it has been reported that catalysts with moderate acidity and open pore structure are the best performing ones. ${ }^{1}$

As in any catalytic system also in wax hydrocracking the desired catalyst properties are good activity, selectivity and stability. With respect to the latter though there are minor causes of deactivation like metal deposition, the main focus for process developers is on coke deposition and sulfur poisoning. The standard hydrotreating catalysts based on $\mathrm{Co}, \mathrm{Ni}$ and Mo possess great resistance to sulfur and work in a sulfided state during operation. ${ }^{2-5}$ Almost all noble metals of group VIII (Pt, Rh, Ir) with the sole exception of Pd are easily poisoned by sulfur and their metallic activity sharply decreases. The great thioresistance and the relatively low manufacturing cost of Co-Ni-Mo catalysts make them the dominating variety in the hydrotreating market. The highly active Co-Ni-Mo based catalyst is also used in the new applications of ultra hydrodesulfurization (UHDS) (e.g. STARS and NEBULA). ${ }^{6}$ It is however known that Co-Ni-Mo catalysts have low activity for eliminating the most refractory sulfur compounds of middle distillates, the substituted dibenzothiophenes. It also happens that no catalyst can perform all functions adequately and specialization is necessary. CoMo catalysts for example are preferred for desulfurization and saturation of olefins and they work at mild process conditions, especially of hydrogen partial pressure. Noble metals have high activity and can thus be operated at low hydrogen pressure but are easily poisoned and they are much more expensive, forcing the implementation of costly metal recovery processes for 
spent catalysts. Even like this many properties of the Group VIII noble metals cannot be easily replicated. $\mathrm{Pd}$ for example has a great capacity for hydrogenating and activating hydrogen and oxygen but also has a high resistance to sulfur poisoning and many of these properties are kept or augmented in the oxidized state. Pd and Pt-Pd supported catalysts are the preferred catalyst for dearomatization. The Pt-Pd alloy is very stable though some inhomogeneity can be seen in the atomic distribution of the surface layer of the particles that are enriched in $\mathrm{Pd}^{7}$

Many reports exist on the properties of Pt-Pd based catalysts, as measured by test reactions with model compounds. However almost none deals with the case of $\mathrm{Pt}-\mathrm{Pd}$ catalysts performing several kinds of reactions simultaneously, in spite of their possible advantages: (i) Pt-Pd has great thioresistance and much of the deposited sulfur can be subsequently reversibly eliminated; (ii) the Pt-Pd alloy is thermally very stable and could be easily regenerated since $\mathrm{Pt}-\mathrm{Pd}$ catalyzes the combustion of carbon deposits by oxygen and does not suffer from extensive sintering; (iii) Pt-Pd has all the desirable properties of the metal function of other catalysts, i.e. it has a high hydrogenating capacity (dearomatization), a good carbon-heteroatom bond cleaving properties (HDS, HDN, HDO) and a good activity and selectivity for cyclic carbon-carbon bond breaking (selective ring opening for cetane improvement, SRO); (iv) some properties of Pt-Pd, particularly thioresistance, can be modified by regulating the acidity of the support. ${ }^{8}$

Depending on the acidity of the support Pt-Pd catalysts could be used for the hydrocracking and hydrodesulfurization of middle distillates. It is not an ideal catalyst for HDS because hydrogenation of olefins cannot be precluded. However it could be used in schemes of dehydrodesulfurization/octane recovery of olefin-containing streams. For the hydrocracking of heavy paraffins its use has already been reported ${ }^{9}$ while its activity in hydroisomerization strongly depends on the porous structure of the support. ${ }^{10-13}$ Recent studies indicate that the selectivity and activity of Pt-Pd catalysts mainly depends on the support acidity and the $\mathrm{Pd} / \mathrm{Pt}$ atomic ratio. Devers et al. ${ }^{14}$ studied Pt-Pd catalysts and found that $\mathrm{Pd}$ increases the fraction of $\mathrm{Pt}$ atoms that are reversibly poisoned while $\mathrm{Pd}$ increases the fraction of those irreversible poisoned. The role of the acidity of the support is controversial. Pawelec et al. ${ }^{15}$ reported that the promoting effect of the support acidity on the dearomatiating activity is kept even after neutralization. Albertazzi et al. ${ }^{16}$ studied the role of the Brönsted acid sites in supported Pd-Pt catalysts for the hydrotreatment of LCO and found that the hydrogenating activity followed the 
order: PdPt-MgAl >> PdPt-PILC > PdPt-MCM-41, while the hydrogenolysis, the ring-opening and the cracking followed an opposite order. Jongpatiwut et al. $^{17}$ found that the hydrogenation of monoaromatics over Pt-Pd/alumina is limited by the strong adsorption of diand triaromatics and that this does not begin until the reaction of the heavier compounds is finished.

For the specific hydrocracking of long paraffins many catalysts have been tried. The conclusions of these studies are that both a relatively strong acid function and a strong metal function are needed in order to keep a stable and reasonably high activity level. ${ }^{18-19}$ Especially selective for the production of isoparaffins are the catalysts based on platinum supported over oxoanion promoted zirconia catalysts, i.e. tungsten-zirconia $\left(\mathrm{Pt} / \mathrm{WO}_{3}-\mathrm{ZrO}_{2}\right)$ and sulfated zirconia $\left(\mathrm{Pt} / \mathrm{SO}_{4}{ }^{2-}-\mathrm{ZrO}_{2}\right)$. Of these catalysts, $\mathrm{Pt} / \mathrm{SO}_{4}{ }^{2-}-\mathrm{ZrO}_{2}$ is the most active and can be used at low temperatures; however it has a lower selectivity to isomers than $\mathrm{Pt} / \mathrm{WO}_{3}$ $\mathrm{ZrO}_{2}{ }^{20-21}$

Zhang et al. ${ }^{22}$ also prepared Pt/WZ catalysts for the reaction of $n$-hexadecane. The acidic properties were tailored to produce a material with mainly sites of mild strength. The report is fairly unique in the sense that their material was completely selective to isomerization.

The objective of this work is to study Pt-Pd/ $/ \mathrm{WO}_{3}-\mathrm{ZrO}$ catalysts for the hydrocracking of long paraffins in the presence of sulfur and aromatic compounds. The need to assess the importance of the processing of waxy feedstocks in the presence of these impurities stems from the fact that pure paraffinic feedstocks from F-T syncrudes can be mixed with other feedstocks coming from the solvent dewaxing of lubes, that could contain heteroatoms, naphthenes and aromatics. Reports on hydrocracking of long paraffins have particularly not addressed this issue, being concentrated on the study of pure paraffinic feedstocks.

$\mathrm{n}$-Hexadecane is used as a model feedstock; carbon disulfide and benzothiophene are used as model sulfur refractory impurities while quinolein was chosen as model nitrogenated poison. These impurities are expected to survive the hydrotreatment procedure of some cuts depending on the severity of the process. Benzene and naphthalene are used as model aromatic impurities. Different $\mathrm{Pt} / \mathrm{Pd}$ atomic ratios and different $\mathrm{WO}_{3}-\mathrm{ZrO}_{2}$ calcination temperatures are used in order to vary the relative activity of the metal and acid functions. The focus of the study is on activity and selectivity in the presence of the mentioned 
impurities. The catalyst was optimized in order to increase the thiotolerance while keeping a high liquid yield and high selectivity to branched products of high octane number.

\section{EXPERIMENTAL}

2.1. Catalysts preparation. $\mathrm{WO}_{3}-\mathrm{ZrO}_{2}$ was prepared from a commercial sample of zirconium hydroxide (Strem Chemicals, $16 \% \mathrm{~W}$ ). This material was pressed in the form of pellets using a die and a hydraulic press $\left(6 \mathrm{Ton} \mathrm{cm}^{-2}\right.$ ), then it was ground in a mortar and sieved to $35-80$ meshes. Finally it was calcined at $800{ }^{\circ} \mathrm{C}$, temperature considered optimal for generating acid sites of adequate concentration and medium acid strength.

Then the $\mathrm{WO}_{3}-\mathrm{ZrO}_{2}$ support was impregnated with a chloroplatinic acid and/or palladium chloride (Sigma-Aldrich, 99.9\%) of adequate volume and concentration in order to get a final content of supported metal of $0.5 \%$ on a mass basis. Using this technique 5 different catalysts were prepared with different amounts of $\mathrm{Pd}$. These catalysts were the corresponding monometallic ones, Pt/WZ and Pd/WZ, and bimetallic PtPd with different atomic ratios, 1:3, 2:2, and 3:1, respectively. The impregnated catalysts were then dried in a stove and calcined in air for $3 \mathrm{~h}$ at $500^{\circ} \mathrm{C}$ for removing water and decomposing the ligands of the metal complexes. Finally they were reduced in hydrogen for $3 \mathrm{~h}$ at $500^{\circ} \mathrm{C}$. The samples thus generated were identified as PtWZ; 3:1PtPdWZ; 2:2PtPdWZ; 1:3PtPdWZ and PdWZ.

$\mathrm{Y}-\mathrm{Al}_{2} \mathrm{O}_{3}-\mathrm{Cl}$ catalysts were prepared using a standard wet impregnation technique. $\mathrm{Y}$ $\mathrm{Al}_{2} \mathrm{O}_{3}(\mathrm{CK} 300$, Ketjen) was used as support. Details about the preparation technique can be found elsewhere. ${ }^{23}$

2.2. Characterization. The final amount of $\mathrm{Pt}$ and $\mathrm{Pd}$ over the catalyst was determined by means of ICP-AES using an ARL 3410 equipment. The solid was dissolved in a solution of $1 \mathrm{ml}$ of sulfuric acid, $3 \mathrm{ml}$ of chlorhydric acid and $1 \mathrm{ml}$ of nitric acid. The $\mathrm{W}$ content was analyzed by X-ray fluorescence in a Rich Seifert Extra-II spectrometer with a Mo anode and $\mathrm{Si}(\mathrm{Li})$ detector.

The affinity of the aromatic, nitrogenated and sulfided adsorbates for the surface of WZ was assessed by means of temperature programmed desorption. The model molecules tested as adsorbates were n-hexadecane, cyclohexane, benzene, naphthalene, thiophene, 
benzothiophene and quinoline. Pentane was used as solvent because of its high volatility and the adsorbate concentration in the impregnating solution was $8 \%$ in all cases. The support used was WZ (without Pt or Pd). The experiment was performed by first soaking the catalyst with the solution, then evaporating the excess of hydrocarbons at room temperature overnight. The samples were first stabilized at $50{ }^{\circ} \mathrm{C}$ in flowing nitrogen to eliminate the solvent and then they were heated from $50{ }^{\circ} \mathrm{C}$ to $600{ }^{\circ} \mathrm{C}$ at a heating rate of $10^{\circ} \mathrm{C} \mathrm{min}^{-1}$. The TPD traces were smoothed and fitted in order to detect the peak positions precisely and then activation energies of the adsorbates were calculated using Redhead's peak maximum method $\left(E_{a c t}=25 R T_{\max }\right){ }^{24}$

The amount and strength of the acid sites of the catalysts was measured by means of temperature programmed desorption of pyridine (Merck, >98\%). Before the test the catalysts were calcined $1 \mathrm{~h}$ at $500{ }^{\circ} \mathrm{C}$, reduced in hydrogen at $300^{\circ} \mathrm{C}$ for $1 \mathrm{~h}$ and cooled down to room temperature in hydrogen at $25^{\circ} \mathrm{C}$. The samples were dipped in a vial containing pyridine and were left unstirred for $6 \mathrm{~h}$. Then they were filtered and let to dry in still air under a fumes hood. Then the samples were put in a quartz reactor under flowing nitrogen and heated at $100{ }^{\circ} \mathrm{C}$ for $1 \mathrm{~h}$ in order to desorb the weakly adsorbed pyridine. The sample was then heated to $650{ }^{\circ} \mathrm{C}$ in flowing nitrogen at a heating rate of $10{ }^{\circ} \mathrm{C} \mathrm{min}-1$. The desorbed products were burned in a flame ionization detector connected on line. The FID signal was sent to a computer and recorded. The sites were classified according to their desorption temperature as weak acid sites $\left(100-250{ }^{\circ} \mathrm{C}\right)$, medium acid strength sites $\left(250-400{ }^{\circ} \mathrm{C}\right)$ and strong acid sites $\left(400-650^{\circ} \mathrm{C}\right)$.

The crystalline structure was assessed by means of X-ray diffraction in a Shimadzu XD1 diffractometer, using CuKa radiation filtered with $\mathrm{Ni}$, in the $2 \Theta$ range of $20-65^{\circ}$ and at a scanning rate of $1.2^{\circ} \mathrm{C} \mathrm{min}^{-1}$.

The textural properties were measured in a Belsorp 28 SA nitrogen adsorption equipment. The specific area $(\mathrm{Sg})$ was obtained by the BET method and the pore size distribution by the D-H (Dollimore-Healy) method.

The reducibility of the metal function of the catalysts was analyzed by means of temperature programmed reduction (TPR) in an Ohkura TP2002 equipped with a thermal conductivity detector. The catalyst samples, calcined and unreduced, were first stabilized in 
Ar at $100^{\circ} \mathrm{C}$, then they were cooled down to room temperature and heated to $800^{\circ} \mathrm{C}$ at $10^{\circ} \mathrm{C}$ $\mathrm{min}^{-1}$ in a stream of $4.8 \% \mathrm{H}_{2}$ in $\mathrm{Ar}$.

2.3. Catalytic test. n-Hexadecane (Merck, $99 \%$ ) was used as a model compound for long heavy paraffins. The hydrocracking tests were performed using a feed of $n$ hexadecane, pure or spiked with sulfur, nitrogen and aromatic compounds. Sulfur compounds were carbon disulfide, thiophene and benzothiophene. Quinoline was chosen as a model aromatic and nitrogen-containing poison similar to benzothiophene in structure and molecular weight. Purely aromatic compounds were benzene and naphthalene. In each test $250 \mathrm{mg}$ of catalysts were used, a flowrate of $n-\mathrm{C}_{16}$ of $0.1 \mathrm{ml} \mathrm{min.}{ }^{-1}$ and a flowrate of $\mathrm{H}_{2}$ of 80 $\mathrm{ml} \mathrm{min} \mathrm{m}^{-1}$ (molar ratio $\mathrm{H}_{2} / \mathrm{nC}_{16}=10$ ). The tubular reactor used was made of AISI 316 stainless steel. It was operated as a three-phase reactor with trickling regime. The $\mathrm{H}_{2}$ flowrate was regulated with a high pressure Cole-Parmer mass flow controller. The reactor pressure was controlled with a Swagelok backpressure regulator. The liquid feed was injected with a ColeParmer HPLC metering piston pump. Before each experiment the catalyst was calcined for 1 $\mathrm{h}$ at $500{ }^{\circ} \mathrm{C}$ in air and reduced in $\mathrm{H}_{2}$ for $1 \mathrm{~h}$ at $300{ }^{\circ} \mathrm{C}$. Then it was stabilized in hydrogen at the temperature of reaction.

The liquid products were separated from the gaseous ones in a gas-liquid separator, after cooling down the product stream to room temperature in a tubular condenser downstream the reactor. The gas product stream was analyzed on-line with a Shimadzu GC$8 \mathrm{~A}$ equipped with a FID and a $100 \mathrm{~m}$ capillary column coated with a squalane phase. The liquid products, collected every $15 \mathrm{~min}$, were analyzed in an SRI gas chromatograph equipped with a dual detector FID/FPD and a $50 \mathrm{~m}$ capillary column CP-Sil PONA CB. The time span of each experiment was $4 \mathrm{~h}$.

Conversion and yield to the different products were calculated from chromatographic data. The compositional data were also used to calculate the RON (Research Octane Number) by means of a simple non-linear correlation published elsewhere. ${ }^{25}$

\section{RESULTS AND DISCUSSION}

3.1. Physicochemical characterization. Values of the Pt and Pd content of the catalysts are included in Table 1. The results coincide with a some error margin with the 
theoretical values expected for a $0.5 \%$ total metal content catalysts with varying Pt:Pd atomic ratios: (pure $\mathrm{Pt}$ ), 3, 2, 1 and 0 (pure $\mathrm{Pd}$ ).

As previously stated the textural properties of the $\mathrm{Pt}$ and $\mathrm{Pd}$ loaded catalysts are practically those of the parent $\mathrm{WO}_{3}-\mathrm{ZrO}_{2}$ catalyst calcined at $800{ }^{\circ} \mathrm{C}$, i.e. $76.3 \mathrm{~m}^{2} \mathrm{~g}^{-1}$ specific surface area, $0.150 \mathrm{~cm}^{3} \mathrm{~g}^{-1}$ pore volume, $6.7 \mathrm{~nm}$ average pore diameter. The total pore volume was distributed mostly in the mesopore range $\left(96 \%\right.$ with $d_{p}=2-20 \mathrm{~nm}, 4 \%$ with $d_{p}>20$ $n m, 0 \%$ with $d_{p}<2$ ) while the micropore volume is negligible. This distribution is favorable for the reaction of moderately large sized molecules such as those present in the cracking of waxy feeds. In this sense, the n-hexadecane molecule has a chain length of $1.4 \mathrm{~nm}$. Benzene and naphthalene molecules have a size of 0.52 and $0.71 \mathrm{~nm}$, respectively. Thiophene, quinolein, and benzothiophene have mean sizes of about $0.45,0.74$ and $0.8 \mathrm{~nm}$. For these molecules there should be no diffusional restrictions.

The $\mathrm{WO}_{3}-\mathrm{ZrO}_{2}$ samples calcined at $800{ }^{\circ} \mathrm{C}$ were mostly tetragonal as measured by $\mathrm{X}$ ray diffraction ( $82 \%$ on a volume basis), in agreement with previous data reported elsewhere for catalysts prepared in a similar way and having similar tungsten loading. ${ }^{26-27}$ Peaks addressed to the tetragonal crystal phase were found at $2 \theta=23.2,23.7$, and $24.4^{\circ}$. These peaks were found also in the Pt and Pd loaded catalysts, with practically no variation in the diffractograms.

The acidity characterization results as obtained by temperature programmed desorption of pyridine is included in Table 2. The base $\mathrm{WO}_{3}-\mathrm{ZrO}_{2}(\mathrm{WZ})$ catalyst had an acid strength distribution with a majority of medium strength acid sites. Weak acid sites are the second more abundant and strong acid sites are scarce, only 6\%. This relative distribution is practically not changed by the addition of $\mathrm{Pt}, \mathrm{Pd}$ or $\mathrm{Pt}$ and $\mathrm{Pd}$. The effect of noble metal doping is that of decreasing the total number of acid sites but no kind of acid sites (weak, mild, strong) is especially affected.

The results that indicate a decrease in the acidity upon noble metal doping must be compared cautiously with other reported results. In this sense it must be stressed that pyridine TPD was performed in the absence of hydrogen using nitrogen as carrier gas. The technique therefore cannot assess the dynamic production of mobile protons in a hydrogen atmosphere, as proposed by many authors for Pt supported over oxoanion promoted zirconia catalyst. The effect in this case has been attributed to dissociation of molecular hydrogen 
followed by subsequent electron abstraction on Lewis surface sites. ${ }^{28}$ Experiences using the same experimental technique of pyridine desorption using a nitrogen carrier were performed by Carvalho et al. ${ }^{29}$ and they reported a similar decrease of the total acidity of the parent chlorided alumina catalyst upon noble metal doping.

The TPR curves of the supported monometallic and bimetallic calcined catalysts are included in Figure 1. The TPR trace of the WZ support (not shown) has only one clear peak at $315{ }^{\circ} \mathrm{C}$ that was attributed to the reduction of $\mathrm{WO}_{3}$ to the substoichiometric oxide $\mathrm{WO}_{2.9}{ }^{31}$ This peak is repeated in the TPR traces of the noble metal catalysts and additional peaks appear at lower temperatures. The reduction of the oxides of $\mathrm{Pt}$ and $\mathrm{Pd}$ seemingly occurs on WZ in an envelope in the $120-230^{\circ} \mathrm{C}$ range. The TPR traces of the monometallic catalysts, PtWZ and PdWZ, indicate that Pt would be reduced at $145^{\circ} \mathrm{C}$ and $\mathrm{Pd}$ at $155^{\circ} \mathrm{C}$.

3.2. Affinity of hydrocarbons for the $\mathrm{WO}_{3}-\mathrm{ZrO}_{2}$ surface. Figure 2 shows the results of the TPD experiments intended at assessing the affinity of hydrocarbons and poisons for the tungsten-zirconia surface.

The results indicate that $n$-hexadecane is mainly desorbed at about $280^{\circ} \mathrm{C}$. This is only a little higher than its normal boiling point, $271^{\circ} \mathrm{C}$, indicating that the interaction between the surface of WZ and n-hexadecane is not strong. In the case of the WZ sample with adsorbed benzene, the TPD trace is similar to that of the catalyst with adsorbed $n$-hexadecane. Benzene has a boiling point of $80.1^{\circ} \mathrm{C}$ and the maximum in the TPD trace is at $270{ }^{\circ} \mathrm{C}$. The great difference between the two temperatures is due to the great affinity of benzene for the acid sites of WZ. The desorption range at $250-600^{\circ} \mathrm{C}$ would correspond to the desorption of benzene molecules located on relatively strong adsorption sites, e.g. mild and strong acid sites as assessed in the pyridine TPD test. The appearance of interactions of different strength between benzene and $W Z$ is easily explained by the electron donor properties of the aromatic ring of benzene and the existence of electrophilic acid sites of varying strength on the surface of tungsten zirconia.

The TPD trace of adsorbed naphthalene has a broad envelope in the $100-470{ }^{\circ} \mathrm{C}$ region. Similarly to benzene, the main desorption peak, is located at $320^{\circ} \mathrm{C}$, a higher temperature than the naphthalene boiling point. The adsorbed amount is however much smaller than in 
the case of benzene and the signal had to be augmented for better visibility. Probably most naphthalene on the WZ support sublimated during the heat pretreatment of the TPD test. However it is also possible that WZ has a decreased capacity for naphthalene adsorption because of some kind of steric hindrance. WZ has mainly Brönsted acid sites that are known to be constrained for adsorption of bulky molecules. This fact has indeed been used to adsorb selectively sterically hindered probe molecules on more accessible Lewis acid sites. This is the case of the technique of dimethyl- and trimethyl- pyridine adsorption for titrating Lewis acid sites. ${ }^{32}$

Quinoline had a TPD trace similar to that of naphthalene, mainly desorbing at low and middle temperatures. The main desorption peak, is located at $330^{\circ} \mathrm{C}$, a higher temperature than its boiling point $\left(238^{\circ} \mathrm{C}\right)$.

The influence of aromaticity in modulating the affinity for the WZ surface becomes clear after the comparison of the TPD traces of benzene and cyclohexane. The main and only TPD peak of the cyclohexane TPD trace $\left(190^{\circ} \mathrm{C}\right)$ is $110^{\circ} \mathrm{C}$ higher than the boiling point for this compound, $80.7{ }^{\circ} \mathrm{C}$. For benzene the temperature difference is $190{ }^{\circ} \mathrm{C}$. The higher adsorption of aromatic molecules is due both to the greater availability of $\pi$ electrons as compared to those of $\sigma$ bonds, and to the greater stability of the charged adsorbed complex. Paying attention only to electron donation properties, Choudhary and Mantri ${ }^{32}$ correlated the position of the main peaks of desorption from their acid support with the ionization potential of the adsorbates. According to the authors the ionization potential is inversely proportional to the temperature of desorption. In our case the order of ionization potential for the involved probe molecules is: cyclohexane $(9.86 \mathrm{eV})>$ benzene $(9.8 \mathrm{eV})>\mathrm{n}$-hexadecane $(8.98 \mathrm{eV})>$ thiophene $(8.91 \mathrm{eV})>$ benzothiophene $(8.73 \mathrm{eV})>$ quinoline $(8.62 \mathrm{eV})>$ napthalene $(8.1 \mathrm{eV})$, while the order for desorption temperature is: cyclohexane $<$ thiophene $<$ benzene $=n$ hexadecane $<$ naphthalene $=$ quinoline $<$ benzothiophene. Obviously the correlation is only approximately correct, because the ionization potential only measures the easiness of taking an electron from molecules but does not reflect the stability of polarized or ionized adsorbates on the acidic surface, probably of the carbenium ion type. This stability may also depend on geometrical factors such as those seemingly operating in the case of naphthalene.

In any case the empirical evidence shows that naphthalene and benzothiophene desorb completely only at very high temperatures and should therefore act as great poisons of the 
acid sites of WZ. The results of deconvolution of the TPD traces and calculation of the activation energies by the Redhead's method, are depicted in Table 3. All traces could be better fitted with a set of gaussian functions, indicating the heterogeneity of the surface and/or the multiple configurations of the adsorbates on the surface. It can be seen that the desorption activation energy was equal to almost three times the heat of vaporization in the case of small cyclic molecules like benzene, cyclohexane and thiophene, but only 1.5 times in the case of bulky molecules like benzothiophene, naphthalene and n-hexadecane. This might indicate that the magnitude of the adsorption interaction is not proportional to the molecule size or in other words, that adsorption on multiple sites does not occur in the case of the bigger molecules.

\subsection{Hydrocracking of $n$-hexadecane. Influence of aromatic impurities and total} pressure. Table 4 shows the effect of total pressure (experimentally obtained results) and the presence of benzene on the conversion and selectivity to light gases $\left(\mathrm{C}_{1-4}\right)$ during the isomerization-cracking of $n$-hexadecane. These tests were performed for screening the pressure range and choosing the best reaction condition. This condition was to be chosen on attention to the RON gain produced by the reaction ( $R O N$ of the $\mathrm{C}_{5}{ }^{+}$liquid fraction minus the RON of the feed).

The pressure screening tests indicate that the best pressure condition in the absence or the presence of benzene is $20 \mathrm{~atm}$. At this pressure value the RON gain of the product is 117 in the absence of benzene and 108 in the presence of benzene. Higher and lower pressure values are accompanied by a decrease in the RON of the liquid product. If the conversion is taken into account this is not maximum at 20 atm but there is not a big difference, with the highest recorded value found at either 15 or 25 atm.

All throughout the pressure range the $n$-hexadecane conversion is lower when the feed contains benzene. So a first effect of benzene in the feed is evidently that of decreasing the activity of the catalyst. This was addressed to an effect of adsorption of benzene on some acid sites. Recalling the TPD results benzene is mainly desorbed from WZ at $200{ }^{\circ} \mathrm{C}$ but desorbs completely only at $250^{\circ} \mathrm{C}$. Hence at the reaction conditions a minor fraction of the acid sites, associated to the stronger ones, would still be covered with benzene. 
Another important effect is that of reducing the production of gases. This is almost null for pressures of 5-15 atm, when conversion values are $23-61 \%$. At 20 and 25 atm the value is not negligible but very small $\left(6.2-8.6 \%\right.$ selectivity to $\left.C_{1-4}\right)$.

The remarkably low cracking and high liquid yield when benzene is present reveals that the presence of aromatics during hydrocracking of long paraffins might be highly desirable. In this sense additional experiments were performed to elucidate the exact pattern of this positive influence. In any case it can be foreseen that the presence of benzene (or aromatics) in the feed would enable more intensive catalytic treatments with higher average residence time such as those related to reactors operated in once-through mode at very low feed space velocity or with recycle of the non-reacted feed. In comparison to the aromatics-free operation, these modes of operation could possibly yield a higher isomerizate RON (for equal liquid yield) or a higher liquid yield (for equal final isomerizate RON).

Cracking proceeds on sites of high acid strength and occurs in parallel with reactions of oligomerization that demand sites of similar strength. In this sense we expected that benzene presence in the feed not only would decrease cracking but also oligomerization and coking. Tests performed with varying benzene concentration (see Table 5) confirmed this supposition. TPO tests on the spent catalysts after the run indicated that the coke content after the run is monotonically decreased from $2.03 \%$ to $0.66 \%$. The nature of the coke deposits can be deduced from the position of the main TPO peak. Low temperature peaks are related to light, low polymerized coke, while high temperature TPO peaks point to heavy, highly polymerized coke deposits. The trend of the results in Table 5 is not clear in this point but on average it can be approximately said that in conditions of high coking rate (low benzene concentration, $0-0.2 \%)$ the coke deposit is light $\left(\mathrm{T}_{\max }<300{ }^{\circ} \mathrm{C}\right)$ while in conditions of low coking rate (high benzene concentration, $1-10 \%)$ the coke deposits are heavy $\left(\mathrm{T}_{\max }>350{ }^{\circ} \mathrm{C}\right)$. A possible explanation of this behavior is found on the ambivalent nature of benzene in relation to coking: on one side it reduces the global coking rate by poisoning strong acid sites; on the opposite side it is itself a coke precursor of low $\mathrm{H} / \mathrm{C}$ ratio, leading to the formation of heavy coke deposits.

On average the effect of increasing the pressure in the 5-25 atm range is mainly that of increasing the conversion and the cracking to light gases and short paraffins but without shifting the center of the distribution by carbon number. The presence of benzene reduces 
the total conversion and the cracking to light gases, and it shifts the center of the product distribution to higher carbon numbers. These are the products of highest RON value in the $\mathrm{C}_{5+}$ cut and for this reason the best reaction pressure for the benzene-doped feed was relatively high, $20 \mathrm{~atm}$.

Additional tests for assessing the influence of the benzene content in the feed were performed and the results can be seen in Figure 3 that shows the influence of benzene content on the selectivity to branched isomers. Small amounts of benzene in the feed, lower than $1 \%$, can produce an increase of almost 5 points in the selectivity (from $84 \%$ to $89 \%$ ). Further additions of benzene do not increase the selectivity much more, and only $94 \%$ selectivity is obtained when the benzene content reaches $10 \%$. With respect to the carbon number $(\mathrm{CN})$ distribution, at low benzene concentration values $(0<\mathrm{Bz}<0.2)$ the product distribution is centered in $\mathrm{CN}=8-9$ and this center is shifted to $\mathrm{CN}=9-10(\mathrm{Bz}=1 \%)$. At very high benzene concentration values $(B z=10 \%)$ only hexadecane isomers are practically produced.

The results of benzene poisoning are easily explained by considering that benzene adsorbs on strong acid sites at the reaction conditions. Small amounts of benzene are enough to poison the stronger sites responsible for cracking and for this reason the selectivity curve first rises steeply and then reaches a plateau. Once all strong acid sites are poisoned, the rest of the benzene can only be adsorbed on sites of mild and weak acid strength. As the strongest acid sites should be responsible for cracking in terminal positions and the formation of light gases, cracking to light gases (undesired) is inhibited first and needs only small amounts of benzene in the feed.

Results of the comparative tests of n-hexadecane hydrocracking in the presence of benzene and naphthalene are included in Table 6 and Figure 4. Naphthalene, like benzene, produces a drop in conversion and a decrease in the selectivity to light gases, but its poisoning effect on the acid sites is not so strong. $1 \%$ benzene produces a $43 \%$ decrease in conversion while $1.3 \%$ naphthalene only $22 \%$. $1 \%$ benzene reduces the selectivity to gases by $94 \%$ while $1.3 \%$ naphthalene by $77 \%$. A higher concentration of naphthalene $(2.6 \%)$ reacting with a similar contact time produces only a slightly higher inhibition of the cracking to light gases. 
The effects of benzene and naphthalene on the shape and center of the product distribution are very similar. Both produce a decrease in the yield to $\mathrm{C}_{4-6}$ isomers (Figure 4) and light gases (Table 6). The product distribution in the $\mathrm{C}_{5}-\mathrm{C}_{10}$ range is flat for a pure $\mathrm{n}$ hexadecane feed with a maximum at $\mathrm{C}_{8}$.

The weaker effect of naphthalene for poisoning the strong acid sites responsible for cracking is difficult to explain. Ania et al. ${ }^{33}$ studied the adsorption of naphthalene over activated carbon and found that the concentration of the adsorbate strongly depends on the pore distribution, particularly the microporosity. The other important factor is the polarity of the solvent, since polar solvents do not favor naphthalene adsorption ${ }^{34}$. Both these two factors, i.e the low polarity of the solution and the absence of microporosity in the support, should favor the adsorption of naphthalene on WZ from paraffinic mixtures. Naphthalene also has a stronger heat of adsorption on acid surfaces than benzene or toluene ${ }^{32}$. The possibility that strong acid sites on WZ are selectively located in small pores of difficult accessibility seems also not likely. Micropores of small diameter are indeed capable of the cooperative action of acid sites on opposite pore walls and can be capable of deep cracking. However this fraction of pores was found to be negligible on WZ, as measured by nitrogen sortometry.

The relatively low effect on reducing the cracking activity only correlates with the low amount of adsorbed naphthalene detected in the TPD tests. The high value of the heat of adsorption of naphthalene would be related to the high temperature of the last peaks of the TPD trace. The low amount of adsorbed naphthalene seems not to be related to some steric hindrance, since the molecular size of naphthalene $(0.71 \mathrm{~nm})$ is similar to that of benzothiophene $(0.8 \mathrm{~nm})$ and smaller to that of $n$-hexadecane $(1.4 \mathrm{~nm})$, that are both adsorbed in higher quantities. Naphthalene is also a planar molecule and should be readily accessible for bonding with the surface.

The results of Figure 4 are a comparison of the product distributions obtained with benzene or naphthalene in the feed. The distribution is very similar for benzene and naphthalene, but the activity with naphthalene is higher. In the case of the TPO tests, the naphthalene feedstock produced a coked catalyst with a $5 \%$ carbon and a peak of temperature combustion at $393^{\circ} \mathrm{C}$. This is a temperature corresponding to a light coke of low polymerization, indicating that there is no much condensation of naphthalene units. 
3.4. Effect of sulfur poisons. Sulfur impurities in the feed produce effects on the catalytic activity and selectivity that are different as those found in the case of the poisoning with benzene and naphthalene. These effects depend also on the kind of sulfur compound involved. In the case of carbon disulfide $\left(\mathrm{CS}_{2}\right)$ a plot of conversion level as a function of sulfur feed concentration is included in Figure 5. These are stable values of conversion at high values of time-on-stream, i.e., values corresponding to a pseudo steady state

$\mathrm{CS}_{2}$ is only a poison of the metal function; however it produces a noticeable decrease of the overall activity of Pt/WZ. Considering that sulfur is adsorbed over the Pt particles it can be rationalized that the capacity for dissociative chemisorption of hydrogen is inhibited. This is a crucial step in the non-classical bifunctional mechanism of isomerization because atomic hydrogen migrates over the surface and forms acid protonic Brönsted isomerization sites by reduction of strong acid sites. ${ }^{35-39}$ In this sense the effect of $\mathrm{CS}_{2}$ would be that of indirectly decreasing the number of Brönsted acid sites of the PtWZ catalyst. It also happens that if dissociated hydrogen is not available, hydride transfer steps, the final steps in the isomerization mechanism, could be inhibited. ${ }^{40-41}$ Finally also hydrogenation of coke precursors could be inhibited by the decreased production of atomic hydrogen and hence the catalyst could deactivate prematurely.

The reasonable limit for $\mathrm{CS}_{2}$ in the feed seems to be 50-60 ppm. At this level of sulfur or at lower levels, $80 \%$ of the original activity can be retained. Bigger sulfur levels produce a total deactivation of the catalyst. The drop in activity is not accompanied by a drastic change in selectivity (see Table 7), though there seems to be an increase in the relative production of light gases as the concentration of $\mathrm{CS}_{2}$ in the feed is augmented. These could be related to the decreased transformation of surface Lewis acids into Brönsted acid sites by reduction with atomic hydrogen. Lewis acid sites on oxoanion promoted zirconia catalysts have been reported to be active sites for deep cracking of liquid paraffins to light gases. ${ }^{42}$

Benzothiophene and dibenzothiophene, the most common refractory sulfur compounds of kerosene and gas oil have both sulfur and aromatic rings. Therefore it is expected that they produce a combination of the effects seen for purely aromatic and purely sulfided compounds.

When performing the hydrocracking on n-hexadecane doped with $50 \mathrm{ppm} \mathrm{S}$ (benzothiophene) at the previous reaction conditions $\left(225^{\circ} \mathrm{C}, 20 \mathrm{~atm}\right)$ the catalyst has no 
activity. Subsequent tests at lower sulfur concentrations show that the catalyst is still deactivated. At a concentration of $10 \mathrm{ppm} \mathrm{S}$ a stable conversion level is finally got. The results obtained from this test are presented in Table 8.

It can be seen that while the reaction using PtWZ and a sulfur-free feed produces mainly products in the $\mathrm{C}_{5-10}$ range, the reaction in the presence of benzothiophene produces mainly hexadecane isomers. Another difference is that in the absence of sulfur there is an almost $10 \%$ yield of light gases while no gases are produced when 10 ppm benzothiophene is present in the feed. This points to the suppression of the acid activity of PtWZ by the action of benzothiophene. It is not possible to say if the effect of poisoning of acid sites by the aromatic nucleus is stronger than the effect of suppression of hydrogen dissociation by sulfur poisoning of the Pt particles.

A comparison of the isomerization-cracking performance of a Pt/WZ catalyst and a classical $\mathrm{Pt} / \mathrm{Al}_{2} \mathrm{O}_{3}-\mathrm{Cl}$ catalyst is made in Table 9. It can be seen that the alumina catalyst has has the highest selectivity to hexadecane isomers but a lower activity for conversion of $n-C_{16}$. When benzothiophene is present in the feed (10 ppm $\mathrm{S}, \mathrm{Pt} / \mathrm{Al}_{2} \mathrm{O}_{3}-\mathrm{Cl}$ catalyst) the hydrocracking is practically suppressed (results not shown) and the selectivity to $\mathrm{C}_{16}$ isomers reaches $92 \%$, though the activity is almost nil $(0.4 \%)$. It can be seen that at the optimal reaction conditions of isomerization-cracking on $\mathrm{Pt} / \mathrm{WZ}^{43}$ the classical chlorided alumina catalyst has a low activity for either isomerization or cracking. This could be due to unfavourable reaction conditions. Hydroisomerization on $\mathrm{Pt} / \mathrm{Al}_{2} \mathrm{O}_{3}-\mathrm{Cl}$ proceeds by a classical bifunctional acid-metal mechanism and too high hydrogen partial pressures result in a decrease of the concentration of olefinic intermediates and hence of the total reaction rate.

3.5. Test of Pt-Pd catalysts. In order to improve the activity in the runs with the benzothiophene contaminated feed, a second metal with higher thioresistance, Pd, was added. Table 10 shows the results related to the performance of the Pt-Pd catalysts when reacting a n-hexadecane feed, pure or spiked with 10 ppm sulfur (as benzothiophene).

When the reaction is performed with pure $n-C_{16}$ deactivation is due solely to coking. When $S$ is present in the feed the activity drops to an even lower level. The results of Table 10 indicate that despite the expectations on the higher thioresistance of Pd, the deactivation 
of the Pd-containing catalyst is even higher. The conversion of PtWZ is $15 \%$ in the presence of sulfur while the best $\mathrm{Pd}$ loaded performing catalyst, $3: 1 \mathrm{PtPd}$ has only $10 \%$ conversion.

The lower activity of the $\mathrm{Pd}$ catalysts is not only a problem of the action of sulfur but also of the intrinsic lower activity in hydrocracking of the Pd catalysts. This is explicit in the first columns of Table 10 that show the performance of all catalysts in the hydrocracking reactions without sulfur. The conversion of PtWZ is $98 \%$ while the best performing catalyst $3: 1 \mathrm{PtPd}$ has only $23 \%$.

The effect of Pd addition in reducing the activity of PtWZ seems not to be related to a modification of the permanent acidity, as measured by the pyridine adsorption technique, that shows that PtWZ has a total acidity of $263 \mu \mathrm{mol}$ Py $\mathrm{gcat}^{-1}$ and 3:1PtPd a value of $212 \mu \mathrm{mol}$ Py $g_{c a t}{ }^{-1}$. It is also not related to the presence of strong acid sites, that are almost the same for both catalysts, 16-14 $\mu \mathrm{mol} \mathrm{Py} \mathrm{g}_{\mathrm{cat}}{ }^{-1}$.

One possible explanation is related to the role of atomic hydrogen in the overall mechanism of hydrocracking. According to many authors on oxoanion promoted zirconia catalysts protons are generated by reduction of Lewis surface acid sites by atomic hydrogen during the reaction. Other authors point to the role of hydride transfer as a final step in the mechanism. In any case in the non-classical bifunctional mechanism, atomic hydrogen generation is crucial. Since $\mathrm{Pt}$ is more active for hydrogen dissociative chemisorption ${ }^{44-45}$ the hydrocracking on long paraffins would be better performed using $\mathrm{Pt}$ as metal function.

On the other hand if a classical mechanism of $n$-hexadecane is invoked, with olefinic intermediates produced on metal sites, a higher de/hydrogenation activity for Pt/WZ in comparison to $\mathrm{Pd} / \mathrm{WZ}$, could explain the activity pattern. Note that we should talk of a higher activity of Pt/WZ rather than a higher activity of $\mathrm{Pt}$ itself, since metal-support interactions are quite important in oxoanion promoted zirconia catalysts. ${ }^{46}$ In any case it is a reported fact that Pt based catalysts are often more active than Pd based ones, for the conversion of middle or long n-alkanes. ${ }^{47}$

Despite the lower activity of Pd promoted catalysts, it can be seen that they are much more thiotolerant. Taking the best performing catalyst of the series for comparison, we can see that 3:1PtPd loses $44 \%$ activity when the feed is switched to a sulfur doped one. The Pt catalyst conversely loses $84 \%$ of its original activity. This point to a possible compromise 
solution of using PtPd catalysts in which the activity is modulated by varying the Pt content mainly, while the thiotolerance is improved by addition of $\mathrm{Pd}$.

With respect to the product distribution $\mathrm{Pd}$ addition completely suppresses the production of light gases though the exact mechanism is not clear. Main products on these catalysts are $\mathrm{n}$-hexadecane isomers and $\mathrm{C}_{5-10}$ isomers, either in the presence of sulfur or not.

With PtWZ and the $\mathrm{nC}_{16}$ feed a cut is obtained with product distribution concentrated in the $\mathrm{C}_{5-10}$ range. With $\mathrm{PdWZ}$ for the pure or benzothiophene (BT) doped feed, selectivity does not change. The presence of BT in the feed displaces the distribution to higher carbon numbers in the case of the bimetallic catalysts, except for the 1:1PtPd catalyst, which has a distribution centered in $\mathrm{CN}=8$. When doping with $\mathrm{BT}$ the rate of adsorption of the reactants is changed. When the feed has no BT and is composed of pure n-hexadecane, a $\mathrm{C}_{4}-\mathrm{C}_{10}$ (no podemos cambiar mucho la version original, por mas que tengas dudas de lo puesto) product cut is mainly obtained. The greatest selectivity to naphthas is obtained with the $3: 1 \mathrm{PtPdWZ}$ catalyst; this selectivity is a little lower than that obtained with the PtWZ catalyst. The addition of $\mathrm{Pd}$ to $\mathrm{Pt}$ modifies this distribution slightly, improving the liquid yield with an important decrease of the production of light gases (see table 10).

With respect to the distribution of products during the reaction of feedstocks doped with BT it can be seen that the Pt catalyst has a lower cracking activity and thus a lower selectivity to naphtha. Its selectivity in the poisoned state is completely biased to the production of branched isomers of hexadecane.

Comparative results on the poisoning effect of benzothiophene and quinoilne are included in Table 11. The poisoning effect is much stronger for benzothiophene. The quinoline poisoned catalyst has almost twice the activity level of the sulfur poisoned catalyst, and a similar selectivity.

With respect to the resistance to sulfur and nitrogen poisoning, according to the relative activity drop (ratio of conversion in the tests with pure and contaminated feed), the most resistant catalysts were the 1:3 and 3:1 PtPd in the case of sulfur poisoning, and the $1: 1$ and 3:1 PtPd in the case of nitrogen poisoning. In all cases the Pt catalysts had the highest activity level and the highest activity drop upon poisoning. The 3:1 PtPd catalyst would be the more stable at most reaction conditions. This is also the second most active catalyst of the series. 
The stronger poisoning effect of benzothiophene can be due to many reasons. At the reaction conditions all tested adsorbates (naphthalene, benzothiophene, thiophene, benzene, etc.) should act as poisons to some extent but the compound desorbing the last in the TPD tests is indeed benzothiophene. In comparison to quinoline and despite its lower basicity benzothiophene displays a stronger adsorption on the strong acid sites of WZ. Benzothiophene is also a strong poison of the metal function. On a thermodynamic basis the total hydrogenation of the ring and hydrogenolysis of the $\mathrm{C}-\mathrm{S}$ (or $\mathrm{C}-\mathrm{N}$ bonds) to $\mathrm{SH}_{2}$ (and $\left.\mathrm{NH}_{3}\right)$ is highly favored $\left(\Delta \mathrm{G}_{\mathrm{r}}\right.$ is $-100 \mathrm{~kJ} \mathrm{~mol}^{-1}$ for quinoline and $-148 \mathrm{~kJ} \mathrm{~mol}^{-1}$ for benzothiophene) and the conversion of the poisons should only be kinetically restricted. In this sense all evidence points to an inhibition of the ring-opening capability of the metal function in oxoanion promoted zirconia catalysts. Watanabe et al. ${ }^{48}$ have reported that the Pt$\mathrm{Pd} /\left[\left(\mathrm{SO}_{4}{ }^{2-}-\mathrm{ZrO}_{2}\right)-\mathrm{Al}_{2} \mathrm{O}_{3}\right]$ catalyst has both hydrodesulfurization and hydroisomerization activity, but that hydrodesulfurization only occurs on isolated $\mathrm{Pd} / \mathrm{Al}_{2} \mathrm{O}_{3}$ sites. Benitez et al. ${ }^{49}$ report that no ring opening products are formed during hydroisomerization of benzene over Pt/WZ. According to Grau et al. ${ }^{50}$ the deficient hydrogenolytic metal properties of Pt would be related to an electron deficiency caused by induction from the oxoanion promoted zirconia support. On the basis of these reports it could be argued that poisoning of the metal function in Pt/WZ occurs by strong chemisorption of the poison on the metal function, but without formation of $\mathrm{SH}_{2}$ or elemental sulfur.

The effect of benzothiophene would be dual because it decreases both the concentration of acid sites and of available metal sites by means of strong chemisorption. For $\mathrm{Pt} / \mathrm{WZ}$ the effect should be drastic due to the role of metal sites on the formation of reactive Brönsted dynamic acid sites (non-classical bifunctional mechanism). ${ }^{51}$

Table 12 shows the values of RON and yield to $\mathrm{C}_{5_{+}}$for the five catalysts studied, for the case of the $\mathrm{n}$-hexadecane feed doped with $10 \mathrm{ppm} \mathrm{S}$. In the computation of the isomerizate properties the contribution of unreacted n-hexadecane has not been included, in order to decouple the effect of low conversion on the Pd catalysts. For the 3:1PtPd ratio the reduction of the deep cracking activity to light gases permits obtaining the highest liquid yield $\mathrm{C}_{5+}$ of the Pd catalysts. This catalyst also produces the products with highest RON (in the Pd catalyst series). In this sense if its activity could be made equal or similar to that of the PtWZ catalyst, it would be the preferred catalyst for this reaction in attention to its sulfur resistance and good selectivity to branched naphtha products. 


\section{CONCLUSIONS}

$\mathrm{Pt} / \mathrm{WZ}$ catalysts for the hydrocracking of long alkanes diplay a great yield to products in the naphtha range and a moderate production of light gases. They are however poisoned by aromatic, sulfur and nitrogen compounds present in the feed.

Aromatic compounds produce a poisoning of the acid active sites that results in a decrease of the hydrocracking activity. Benzene is a stronger poison than naphthalene.

The poisoning effect of benzene is highly beneficial to the selectivity of the reaction, greatly suppressing the production of low value light gases. In this sense a small level of benzene is enough for producing this effect, higher contents being deleterious to the activity without increasing the selectivity further. The optimal amount seems to be $0.5 \%$. The beneficial effect of benzene is addressed to the poisoning of very strong acid sites. Both benzene and naphthalene increase the coking due to their aromatic nature.

Sulfur in the feed is highly deletereous to the activity of PtWZ. This is completely suppressed at levels of $100 \mathrm{ppm}$ in the case of carbon disulfide and $50 \mathrm{ppm}$ in the case of benzothiophene. The latter was the strongest of all poisons tested and affected both the acid and metal functions.

$\mathrm{Pd}$ addition has a beneficial effect on the thioresistance properties of the WZ catalyst but produces catalysts less active in hydrocracking. The most active and thioresistant PtPd/WZ catalyst was the one with a $3: 1 \mathrm{Pt}: \mathrm{Pd}$ atomic ratio.

\section{AUTHOR INFORMATION}

Telephone: +54-324-4533858. E-mail: mbusto@fiq.unl.edu.ar.

\section{ACKNOWLEDGEMENTS}

The research was sponsored by Argentina National Research Council (CONICET, PIP Grant 11220090100684) and Universidad Nacional del Litoral (CAI+D Grants 12/Q 296 and 12/Q 298). 


\section{REFERENCES}

(1) Park, K. -C; Ihm, S. -K Appl. Catal. 2000, 203, 201-209.

(2) Hensen, E. J. M.; Beer, V. H. J.; van Veen, J. A. R.; van Santen, R. A. J. Catal. 2003, 215, 353-357.

(3) Rayo, P.; Ramírez, J.; Rana, M. S.; Ancheyta, J.; Aguilar-Elguézabal, A. Ind. Eng. Chem. Res. 2009, 48, 1242-1248.

(4) Rayo, P.; Ramírez, J.; Torres-Mancera, P.; Marroquín, G.; Maity, S. K. Fuel 2012, 100 , 34-42.

(5) Ding, Lianhui; Zheng, Y.; Zhang, Z.;. Ring, Z.; Chen, J. Appl. Catal. A: Gen. 2007, 319, 25-37.

(6) Plantenga, F. L.; Leliveld, R. G. Appl. Catal. A: Gen. 2003, 248, 248-253.

(7) Fiermans, L.; De Gryse, R.; De Doncker, G.; Jacobs, P. A.; Martens, J.A. J. Catal. 2000,193, 108-144.

(8) Williams, M. F.; Sievers, C.; Van Veen, J. A. R.; Lercher, J. A. XIII ICC, Paris, France 2004, Poster Session, P4-024, July 11-16.

(9) Mériaudeau, P. ; Tuan, V. A. ; Sapaly, G. ; Nghiem, V. T. ; Naccache, C. Catal. Today 1999, 49, 285-292.

(10) Geng, C. H.; Zhang, F.; Gao, Z. X.; Zhao, L. F.; Zhou, J.L. Catal. Today 2004, 93, 485-491.

(11) Claude, M. C.; Vanbutsele, G.; Martens, J. A. J. Catal. 2001, 203, 213-231.

(12) Parton, R.; Uytterhoeven, L.; Martens, J. A.; Jacobs, P. A.; Froment, G. F. Appl. Catal. 1991, 76, 131-142.

(13) Martens, J. A.; Jacobs, P. A. Zeolites 1986, 6, 334-348.

(14) Devers, E.; Geantet, C.; Vrinat, M.; Zotin, J. L. XIII ICC, Paris, France, 2004, Poster Session, P4-0432, July 11-16.

(15) Pawelec, B.; Mariscal, R.; Navarro, R. M.; Van Bokhorst, S.; Rojas, S.; Fierro, J. L. G. Appl. Catal. 2002, 225, 223-237.

(16) Albertazzi, S.; Faraone, C.; Lenarda, M.; Storaro, L.; Talon, A.; Vaccari, A. XIII ICC, Paris, France 2004, Poster Session, P4-044, July 11-16.

(17) Jongpatiwut, S.; Lia, Z.; Resasco, D. E.; Alvarez, W. E.; Sughrue, E. L. Appl. Catal. 2004, 262, 241-253.

(18) Rezgui, Y.; Guemini, M. Appl. Catal. A: Gen. 2005, 282, 45-53. 
(19) Cho, K. M.; Park,S.; Seo, J. G.; Youn, M. H.; Baeck, S. -H.; Jun, K. -W.; Chung, S. J.; Song, I. K. Appl. Catal., B 2008, 83, 195-201.

(20) Busto, M.; Grau, J. M.; Vera, C. V. Appl. Catal. A: Gen. 2010, 387, 35-44.

(21) Busto, M.; Grau, J. M.; Vera, C. R. Fuel Proc. Tech. 2011, 92, 1675-1684.

(22) Zhang, S.; Zhang, Y.; Tierney, J.W.; Wender, I.; Appl. Catal. 2000, 193, 155-171.

(23) Mariscal, R.; Fierro, J. L. G.; Yori, J. C.; Parera, J. M.; Grau, J. M. Appl. Catal. A Gen. 2007, 324, 123-131.

(24) Redhead, P. A. Vacuum 1962, 12, 203-211.

(25) Nikolaou, N.; Papadopoulos, C. E.; Gaglias, I. A.; Pitarakis, K. G. Fuel 2004, 83, $517-$ 523.

(26) Lee, J. S.; Yoon, J. W.; Halligudi, S. B.; Chang, J. S.; Jhung, S. H. Appl. Catal. A: Gen. 2009, 366, 299-303.

(27) Sarish, S.; Devassy, B. M.; Böhringer, W.; Fletcher, J.; Halligudi, S. B. J. Mol. Catal. A: Chem. 2005, 240, 123-131.

(28) Triwahyono, S.; Yamada, T.; Hattori, H. Appl. Catal. A: Gen. 2003, 242, 101-109.

(29) Carvalho, L. S.; Pieck, C. L.; Rangel, M. C.; Fígoli, N. S.; Vera, C. R.; Parera, J. M. Appl. Catal. A: Gen. 2004, 269, 105-116.

(30) Bedia, J.; Gómez-Sainero, L. M.; Grau, J. M.; Busto, M.; Martin-Martinez, M.; Rodríguez, J. J. J. Catal. 2012, 294, 207-215.

(31) Falco, M. G.; Canavese, S. A.; Fígoli, N. S. Cat. Today 2005, 107, 778-784.

(32) Choudhary, V. R.; Mantri, K. Microporous and Mesoporous Mater. 2000, 40, 127-133.

(33) Ania, C. O.; Cabal, B.; Pevida, C.; Arenillas, A.; Parra, J. B.; Rubiera, F.; Pis, J. J. Appl. Surf. Sci. 2007, 253, 5741-5746.

(34) Cabal, B.; Ania, C. O.; Parra, J. B.; Pis, J. J. Chemosphere 2009, 76, 433-438.

(35) Ebitani, K.; Konishi, J.; Hattori, H. J. Catal. 1991, 130, 257-267.

(36) Triwahyono, S., Jalil, A. A., Mukti, R. R., Musthofa, M., Razali, N. A. M., Aziz, A. A. A., Appl. Catal. A: Gen. 2011, 407, 91-99.

(37) Shimizu, K.; Chinzei, I.; Nishiyama, H.; Kakimoto, S.; Sugaya, S.; Yokoi, H.; Satsuma, A. Sens. Actuators B 2008, 134, 618-624.

(38) Ebitani, K.; Tsuji, J.; Hattori, H.; Kita, H. J. Catal. 1992, 135, 609-617.

(39) Shishido, T.; Hattori, H. Appl. Catal. A 1996, 146, 157-164.

(40) Barton, D. G.; Soled, S. L.; Meitzner, G. D.; Fuentes, G. A.; Iglesia, E. J. Catal. 1999, $181,57-72$. 
(41) Iglesia, E.; Soled, S. L.; Kramer, G.M. J. Catal. 1993, 144, 238-253.

(42) Mizuno, K.; Ikeda, M.; Imokawa, T.; Take, J.; Yoneda, Y. Bull. Chem. Soc. Jpn. 1976, 49, 1788-1793.

(43) Busto, M.; Grau, J. M.; Vera, C. R. Appl. Catal. A Gen. 2010, 387, 35-44

(44) Iglesia, E.; Barton, D. G.; Soled, S. L.; Miseo, S.; Baumgartner, J. E.; Gates, W. E.; Fuentes, G. A.; Meitzner, G. D. Stud. Surf. Sci. Catal. 1996, 101, 533-542.

(45) Vaudagna, S. R.; Canavese, S. A.; Comelli, R. A.; Fígoli, N.S. Appl. Catal. A:Gen. 1998, 168, 93-111.

(46) Yori, J. C.; Pieck, C. L.; Parera, J. M. Appl. Catal. A: Gen. 1999, 181, 5-14.

(47) Barrera, A.; Montoya, J. M.; Viniegra, M.; Navarrete, J.; Espinosa, G.; Vargas, A.; Angela, P.; Pérez, G. Appl. Catal.A: Gen. 2005, 290, 97-109.

(48) Watanabe, K.; Kawakami, T.; Baba, K.; Oshio, N.; Kimura, T. Appl. Catal. A: Gen. 2004, 276, 145-153.

(49) Benitez, V. M.; Grau, J. M.; Yori, J. C.; Pieck, C. L.; Vera, C. R., Energy \& Fuels 2006, 20, 1791-1798.

(50) Grau, J. M.; Yori, J. C.; Vera, C. R.; Lovey, F. C.; Condó, A. M.; Parera, J. M. Appl. Catal. A: Gen. 2004, 265, 141-152.

(51) Iglesia, E.; Barton, D. G.; Biscardi, J. A.; Gines, M. J. L.; Soled, S. L. Catal. Today 1997, 38, 339-360. 


\section{Figure captions}

Figure 1. TPR tests of the catalysts as previously reported ${ }^{30}$ : (a) PtWZ; (b) 3:1PtPdWZ; (c) 2:2PtPdWZ; (d) 1:3PtPdWZ; (e) PdWZ

Figure 2. TPD tests of WZ catalysts impregnated with different adsorbates. Cyclohexane. (b) Benzothiophene. (c) Thiophene. (d) Naphthalene (signal multiplied by a factor of 3). (e) Benzene. (f) n-Hexadecane. (g) Quinoline.

Figure 3. n-Hexadecane hydrocracking. Effect of benzene content (volumetric percentage) in the feed. $\left(^{*}\right)$ Conversion. $(\bullet)$ Selectivity to liquid branched products $\left(\mathrm{i}-\mathrm{C}_{4}\right.$ not included).

Figure 4. n-Hexadecane hydrocracking. Distribution of isomers by carbon number. ( n-hexadecane feed. ( $\square$ ) n-hexadecane doped with benzene; ( $\square$ ) n-Hexadecane doped with naphthalene. Reaction conditions: $225{ }^{\circ} \mathrm{C}, 20 \mathrm{~atm}, \mathrm{H}_{2} / \mathrm{HC}=10, \mathrm{WHSV}=18.4 \mathrm{~h}^{-1}$, time-onstream $=1 \mathrm{~h}$.

Figure 5. Conversion of $n$-hexadecane as a function of the concentration of $\mathrm{CS}_{2}$ in the feed. Reaction conditions: $225^{\circ} \mathrm{C}, 20 \mathrm{~atm}, \mathrm{H}_{2} / \mathrm{HC}=10, \mathrm{WHSV}=18.4 \mathrm{~h}^{-1}$, time-on-stream $=1 \mathrm{~h}$. 
Table 1. Catalysts Noble Metal Content.

\begin{tabular}{c|cc|}
\hline Catalyst & \multicolumn{2}{c}{ Content [weight \%] } \\
\hline PtWZ & Pt & Pd \\
3:1 PtPdWZ & 0.55 & 0.00 \\
2:2 PtPdWZ & 0.38 & 0.08 \\
1:3 PtPdWZ & 0.25 & 0.18 \\
PdWZ & 0.00 & 0.33 \\
\hline
\end{tabular}


Table 2. Acidity of $\mathrm{WO}_{3}-\mathrm{ZrO}_{2}(\mathrm{WZ})$ Catalysts.

\begin{tabular}{ccccc}
\multirow{2}{*}{ Catalyst } & \multicolumn{4}{c}{ Acidity, $\mu \mathrm{mol}$ Py $\mathrm{g}_{\mathrm{cat}}{ }^{-1}$} \\
\cline { 2 - 5 } & Weak & Medium & Strong & Total \\
PtWZ & 61.4 & 186.0 & 16.0 & 263.4 \\
3:1PtPdWZ & 30.7 & 161.7 & 14.3 & 211.6 \\
2:2PtPdWZ & 34.3 & 159.0 & 13.5 & 202.9 \\
1:3PtPdWZ & 41.5 & 153.7 & 10.1 & 198.6 \\
PdWZ & 57.8 & 167.1 & 9.30 & 226.7
\end{tabular}


Table 3. Desorption Activation Energy (Ea) as Measured by Readhead's Method.

\begin{tabular}{|c|c|c|c|c|}
\hline Adsorbate & $\begin{array}{l}\text { Number of fitting } \\
\text { Gauss functions }\end{array}$ & $\begin{array}{l}\mathrm{T}_{\max } \\
{ }^{\circ} \mathrm{C}\end{array}$ & $\begin{array}{c}\text { Ea, } \\
\mathrm{kCal} \mathrm{mol}^{-1}\end{array}$ & $\begin{array}{l}\text { Heat of vaporization, } \\
\qquad \mathrm{kCal} \mathrm{mol}{ }^{-1}\end{array}$ \\
\hline \multirow[t]{4}{*}{ Cyclohexane } & 1 peak $\left(R^{2}=0.951\right)$ & 195.7 & 23.29 & 7.14 \\
\hline & 3 peaks $\left(R^{2}=0.998\right)$ & 192.4 & 23.13 & \\
\hline & & 254.72 & 26.22 & \\
\hline & & 448.93 & 35.87 & \\
\hline \multirow[t]{3}{*}{ Benzothiophene } & 3 peaks $\left(R^{2}=0.999\right)$ & 289.85 & 27.97 & 17.82 \\
\hline & & 388.16 & 32.85 & \\
\hline & & 471.4 & 36.99 & \\
\hline Thiophene & 1 peak $\left(R^{2}=0.972\right)$ & 226.69 & 24.83 & 8.28 \\
\hline \multirow[t]{5}{*}{ Naphthalene } & 5 peaks $\left(R^{2}=0.999\right)$ & 179.26 & 22.48 & 16.87 \\
\hline & & 247.41 & 25.86 & \\
\hline & & 310.59 & 29.00 & \\
\hline & & 208.31 & 23.92 & \\
\hline & & 430.99 & 34.98 & \\
\hline \multirow[t]{3}{*}{ Benzene } & 1 peak $\left(R^{2}=0.967\right)$ & 268.39 & 26.90 & 7.31 \\
\hline & 2 peaks $\left(R^{2}=0.991\right)$ & 203.29 & 23.67 & \\
\hline & & 323.4 & 29.64 & \\
\hline \multirow[t]{4}{*}{ n-Hexadecane } & 1 peak $\left(R^{2}=0.962\right)$ & 259.72 & 26.47 & 19.38 \\
\hline & 3 peaks $\left(R^{2}=0.996\right)$ & 228.33 & 24.91 & \\
\hline & & 279.52 & 27.46 & \\
\hline & & 452.17 & 36.03 & \\
\hline
\end{tabular}




\section{Table 4. n-Hexadecane Reaction Results. Tests With a Pure Feed and With a Feed Doped with Benzene (4\% vol/vol). ${ }^{1}$}

\begin{tabular}{|c|c|c|c|c|c|c|c|c|c|c|}
\hline Feed & & & $-C_{16}$ & & & & $n-C$ & $16+B \epsilon$ & nzene & \\
\hline $\mathrm{H}_{2}$ pressure, atm & 5 & 10 & 15 & 20 & 25 & 5 & 10 & 15 & 20 & 25 \\
\hline$\triangle \mathrm{RON}$ & 69.9 & 75.4 & 102 & 117 & 114 & 69.2 & 68.7 & 73.3 & 108.1 & 66.8 \\
\hline Conversion. \% & 41.7 & 61.7 & 84.3 & 98.2 & 96.5 & 22.9 & 28.9 & 61.3 & 58.8 & 46.9 \\
\hline $\mathrm{S}_{\text {gases }} \mathrm{C}_{1-4}, \%$ & 5.2 & 3.4 & 13.1 & 10.2 & 27.7 & 0.7 & 0.26 & 0.72 & 6.2 & 8.6 \\
\hline Liquid yield $\mathrm{C}_{5}{ }^{+}, \%$ & 39.5 & 59.6 & 73.3 & 88.2 & 69.8 & 22.7 & 28.8 & 60.9 & 55.2 & 42.9 \\
\hline
\end{tabular}


Table 5. Temperature Programmed Oxidation Results. Analysis of Spent Catalysts Coked for $4 \mathrm{~h}$ at $225^{\circ} \mathrm{C}, 20 \mathrm{~atm}, \mathrm{H}_{2} / \mathrm{HC}=10, \mathrm{WHSV}=18.4 \mathrm{~h}^{-1}$.

\begin{tabular}{c|cccccc} 
Benzene content, \% & 0 & 0.02 & 0.2 & 1 & 5 & 10 \\
Coke content, \% & 2.03 & 1.98 & 1.24 & 1.05 & 0.75 & 0.66 \\
$\mathrm{~T}_{\max },{ }^{\circ} \mathrm{C}$ & 295.6 & 297.8 & 289.7 & 359.3 & 351.7 & 352.3
\end{tabular}


Table 6. Distribution of Reaction Products. Reaction of $n$-Hexadecane $\left(n-C_{16}\right)$ Doped with Naphthalene (Nt) or Benzene (Bz). ${ }^{1}$

\begin{tabular}{|c|c|c|c|c|c|}
\hline Feedstock & Conversion, & & Select & ity, \% & \\
\hline composition, vol \% & $\%$ & $\mathrm{C}_{5}-\mathrm{C}_{10}$ & $\mathrm{C}_{11}-\mathrm{C}_{15}$ & iso- $\mathrm{C}_{16}$ & Gases \\
\hline$n-C_{16}$ & 98.2 & 73.6 & 13.55 & 2.65 & 10.2 \\
\hline $\mathrm{n}-\mathrm{C}_{16}+\mathrm{Nt}(1.3 \%)$ & 76.4 & 77.1 & 4.3 & 15.6 & 3.0 \\
\hline $\mathrm{n}-\mathrm{C}_{16}+\mathrm{Nt}(2.6 \%)$ & 65.5 & 74.5 & 4.1 & 18.5 & 2.9 \\
\hline $\mathrm{n}-\mathrm{C}_{16}+\mathrm{Bz}(1.0 \%)$ & 56.4 & 63.8 & 6.7 & 28.4 & 1.1 \\
\hline
\end{tabular}


Table 7. Reaction of $n$-Hexadecane Doped with $S_{2} C$. Conversion and Distribution of Products. ${ }^{1}$

\begin{tabular}{|c|c|c|c|c|c|}
\hline $\begin{array}{c}\text { Sulfur } \\
\text { concentration, } \\
\text { ppm }\end{array}$ & $\begin{array}{c}\text { Conversion, } \\
\%\end{array}$ & $\begin{array}{c}\text { Sases, } \\
\%\end{array}$ & $\begin{array}{c}\mathrm{S}_{\mathrm{C} 5-\mathrm{C} 10} \\
\%\end{array}$ & $\begin{array}{c}\mathrm{S}_{\mathrm{C} 11-\mathrm{C} 15}, \\
\%\end{array}$ & $\begin{array}{c}\mathrm{S}_{i-\mathrm{C} 16}, \\
\%\end{array}$ \\
\hline 0 & 98.2 & 10.2 & 73.6 & 13.5 & 2.6 \\
\hline 2 & 74.6 & 4.8 & 87.8 & 4.5 & 2.9 \\
\hline 6 & 77.7 & 0.9 & 84.8 & 9 & 5.3 \\
\hline 60 & 65.6 & 0.6 & 48.9 & 15 & 35.5 \\
\hline 120 & 6 & 0 & 0 & 0 & 100 \\
\hline
\end{tabular}


Table 8. Reaction of $\mathbf{n}$-Hexane Doped with Benzothiophene. ${ }^{1}$

\begin{tabular}{cccccc}
$\begin{array}{c}\text { Sulfur } \\
\text { concentration, } \\
\text { ppm }\end{array}$ & $\begin{array}{c}\text { Conversion, } \\
\%\end{array}$ & $\begin{array}{c}\text { Yield } \\
\text { Gases, } \%\end{array}$ & $\begin{array}{c}\text { Yield } \\
\mathrm{C}_{5}-\mathrm{C}_{10}, \%\end{array}$ & $\begin{array}{c}\text { Yield } \\
\mathrm{C}_{11}-\mathrm{C}_{15}, \%\end{array}$ & $\begin{array}{c}\text { Yield } \\
\text { - } \mathrm{C}_{16}, \%\end{array}$ \\
\hline 0 & 98.2 & 10 & 72.3 & 13.3 & 2.6 \\
10 & 15.1 & 0.0 & 4.6 & 1.6 & 8.9 \\
& & & & & \\
${ }^{1}$ Reaction conditions: $225^{\circ} \mathrm{C}, 20 \mathrm{~atm}, \mathrm{H}_{2} / \mathrm{HC}=10, \mathrm{WHSV}=18.4 \mathrm{~h}^{-1}$, time-on-stream $=1 \mathrm{~h}$.
\end{tabular}


Table 9. Comparison of a Pt/WZ and a $\mathrm{Pt} / \mathrm{Al}_{2} \mathrm{O}_{3}-\mathrm{Cl}$ catalysts. Reaction of $n$-hexadecane $\left(n-C_{16}\right){ }^{1}$

\begin{tabular}{cccccc} 
Catalyst & Conversion, \% & \multicolumn{4}{c}{ Selectivity, \% } \\
\hline $\mathrm{Pt}(0.5 \%) \mathrm{WZ}$ & 98.2 & 73.6 & 13.5 & 2.6 & 10.2 \\
$\mathrm{Pt}(0.5 \%) / \mathrm{Al}_{2} \mathrm{O}_{3}-\mathrm{Cl}$ & 27.5 & 35 & 9.7 & 55.9 & ----
\end{tabular}

${ }^{1}$ Reaction conditions: $225^{\circ} \mathrm{C}, 20 \mathrm{~atm}, \mathrm{H}_{2} / \mathrm{HC}=10, \mathrm{WHSV}=18.4 \mathrm{~h}^{-1}$, time-on-stream $=1 \mathrm{~h}$. 
Table 10. Results of $\mathbf{n}$-Hexadecane Hydrocracking on Pt-Pd catalysts. Comparison of Results with Sulfur-free Feed and Sulfur-doped Feed. ${ }^{1}$

\begin{tabular}{|c|c|c|c|c|c|c|c|c|c|c|}
\hline \multirow{2}{*}{$\begin{array}{c}\text { Feed } \\
\text { Catalyst }\end{array}$} & \multicolumn{5}{|c|}{$\mathrm{n}-\mathrm{C}_{16}$} & \multicolumn{5}{|c|}{$\mathrm{n}-\mathrm{C}_{16}+10 \mathrm{ppm} \mathrm{S}$} \\
\hline & $\mathrm{Pt}$ & 3:1PtPd & 1:1PtPd & $1: 3 \mathrm{PtPd}$ & $\mathrm{Pd}$ & $\mathrm{Pt}$ & 3:1PtPd & 1:1PtPd & 1:3PtPd & $\mathrm{Pd}$ \\
\hline Conversion, & & & & & & & & & & \\
\hline$\%$ & 98.2 & 23.0 & 14.6 & 7.1 & 5.4 & 15.1 & 10.0 & 5.8 & 5.8 & 2.7 \\
\hline $\mathrm{S}_{\text {Gases }}, \%$ & 10.0 & 0.0 & 0.0 & 0.0 & 0.0 & 0.0 & 0.0 & 0.0 & 1 & 0.4 \\
\hline $\mathrm{S}_{\mathrm{C} 5-\mathrm{C} 10}, \%$ & 73.6 & 75.8 & 51.0 & 45.5 & 40.1 & 30.6 & 25.4 & 51.6 & 46.3 & 31.5 \\
\hline $\mathrm{S}_{\mathrm{C} 11-\mathrm{C} 15}, \%$ & 13.5 & 7.2 & 9.3 & 6.9 & 5.5 & 10.3 & 0.0 & 0.0 & 8.4 & 7.3 \\
\hline$S_{i-C 16}, \%$ & 2.6 & 17.0 & 39.7 & 47.6 & 54.4 & 59.1 & 74.6 & 48.4 & 44.3 & 60.8 \\
\hline
\end{tabular}


Table 11. Reaction of $\mathbf{n}$-hexadecane doped with quinoline. ${ }^{1}$

\begin{tabular}{cccccc} 
Feed & \multicolumn{5}{c}{$\mathrm{n}_{16}+10 \mathrm{ppm} \mathrm{N}$} \\
Catalyst & $\mathrm{Pt}$ & $3: 1 \mathrm{PtPd}$ & $1: 1 \mathrm{PtPd}$ & $1: 3 \mathrm{PtPd}$ & $\mathrm{Pd}$ \\
Conversion, \% & 32.8 & 20.8 & 14.5 & 5.1 & 4.3 \\
$\mathrm{~S}_{\text {Gases }}, \%$ & 0.0 & 0.0 & 0.0 & 0.0 & 0.0 \\
$\mathrm{~S}_{\mathrm{C} 5-\mathrm{C} 10}, \%$ & 60.8 & 62.4 & 26.0 & 17.4 & 12.2 \\
$\mathrm{~S}_{\mathrm{C} 11-\mathrm{C} 15}, \%$ & 8.1 & 8.1 & 10.9 & 2.3 & 7.3 \\
$\mathrm{~S}_{\mathrm{i}-\mathrm{C} 16}, \%$ & 31.1 & 29.5 & 63.1 & 80.3 & 80.5 \\
${ }^{1}$ Reaction conditions: $225^{\circ} \mathrm{C}, 20 \mathrm{~atm}, \mathrm{H}_{2} / \mathrm{HC}=10$, WHSV $=18.4 \mathrm{~h}^{-1}$, time-on-stream $=1 \mathrm{~h}$. PtPd/WZ catalysts.
\end{tabular}


Table 12. Some Properties of the Product Isomerizate (RON and selectivity to $C_{5}-C_{10}$ Naphtha, Unreacted n-Hexadecane not included) and RON Gain Obtained With Different WZ Catalysts. ${ }^{1}$

$\begin{array}{lccc}\text { Catalyst } & \begin{array}{l}\text { Liquid products } \\ \text { RON }\end{array} & \text { RON gain } & \text { Selectivity } \\ \text { PtWZ } & 1.7 & 11.2 & \mathrm{C}_{5-10}, \% \\ \text { 3:1PtPdWZ } & 1.5 & 7.9 & 30.6 \\ \text { 1:1PtPdWZ } & 1.2 & 4.8 & 25.4 \\ 1: 3 \text { PtPdWZ } & 0.8 & 4.4 & 51.6 \\ \text { PdWZ } & 0.4 & 2.1 & 31.5 \\ & & \end{array}$




\section{Figure 1}

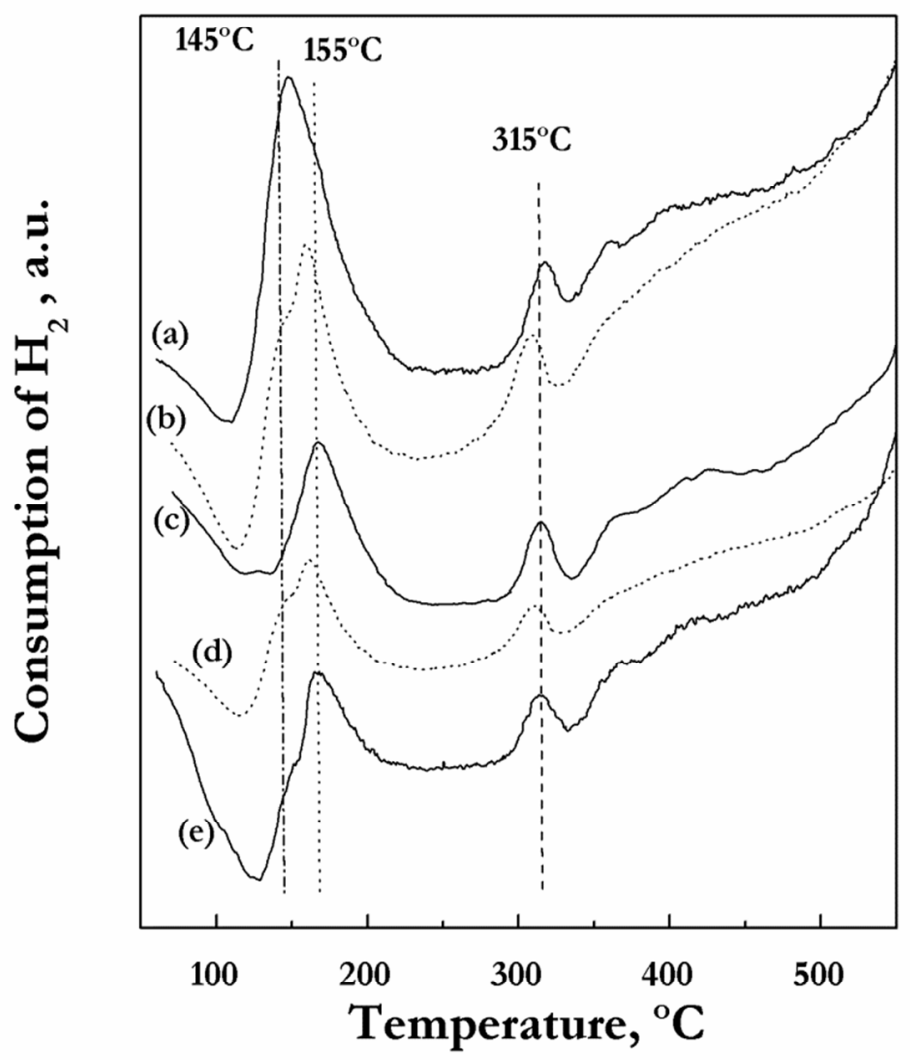

ACS Paragon Plus Environment 


\section{Page 39 of 42}

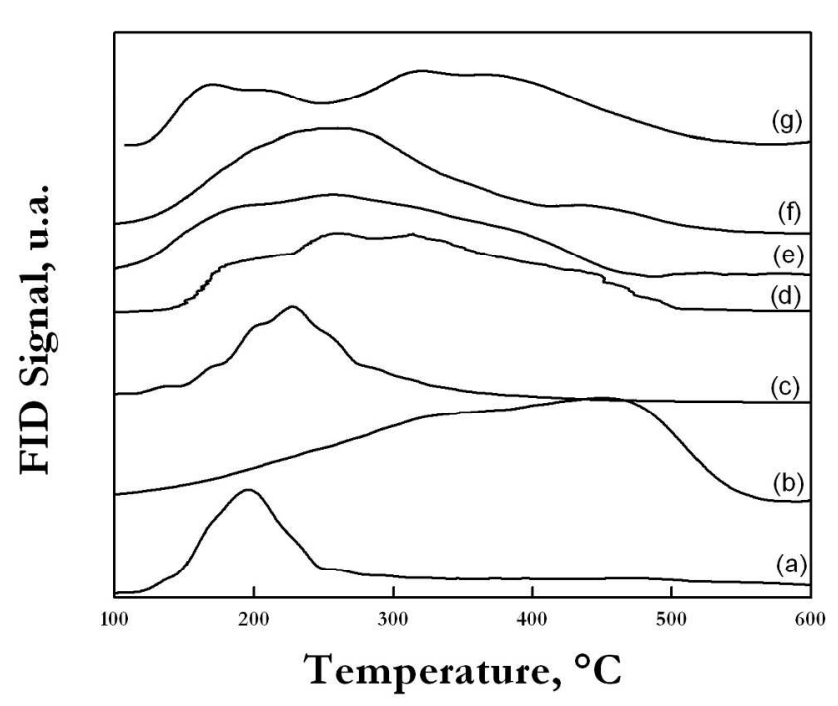

1

2

3

4

5

6
7

8

9

10

11

12

13
14

15

16

17

18

19

20

21

22

23

24

25

26

27

28

29

30

31

32

33

34

35

36

37

38

39

40

41

42

43

44

45

46

47

48

49

50

51

52

53

54

55

56

57

58

59

60

\section{Figure 2}




\section{Figure 3}

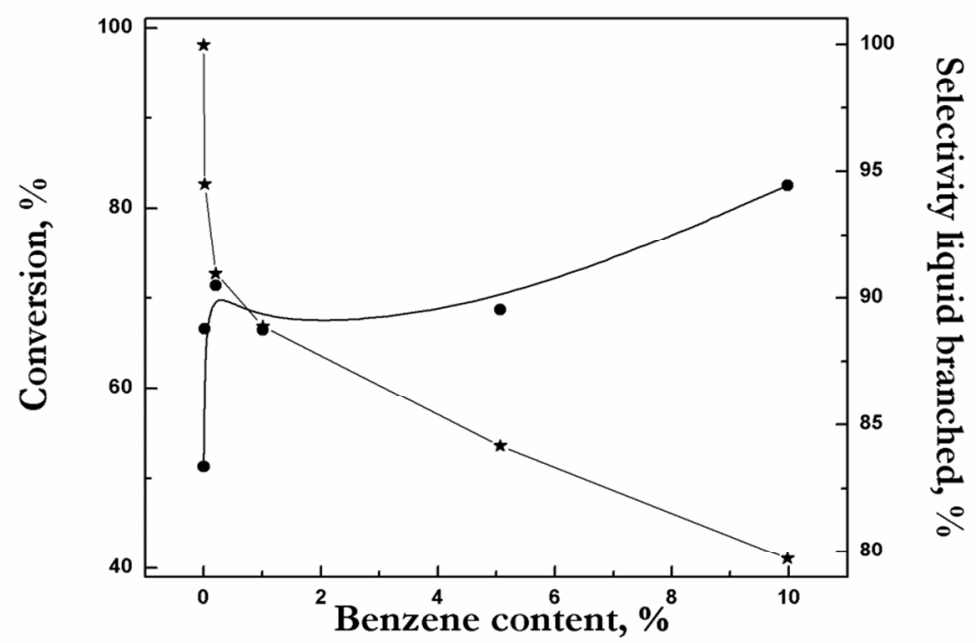




\section{Figure 4}

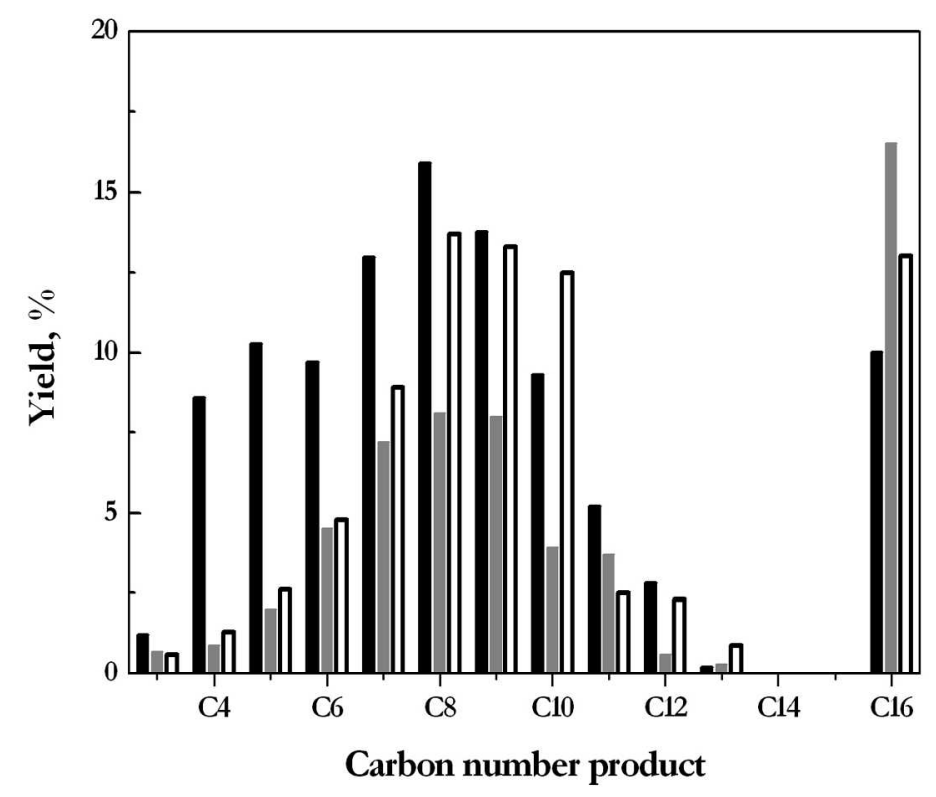

26

27

28

29

30

31

32

33

34

35

36

37

38

39

40

41

42

43

44

45

46

47

48

49

50

51

52

53

54

55

56

57

58

59

60 


\section{Figure 5}

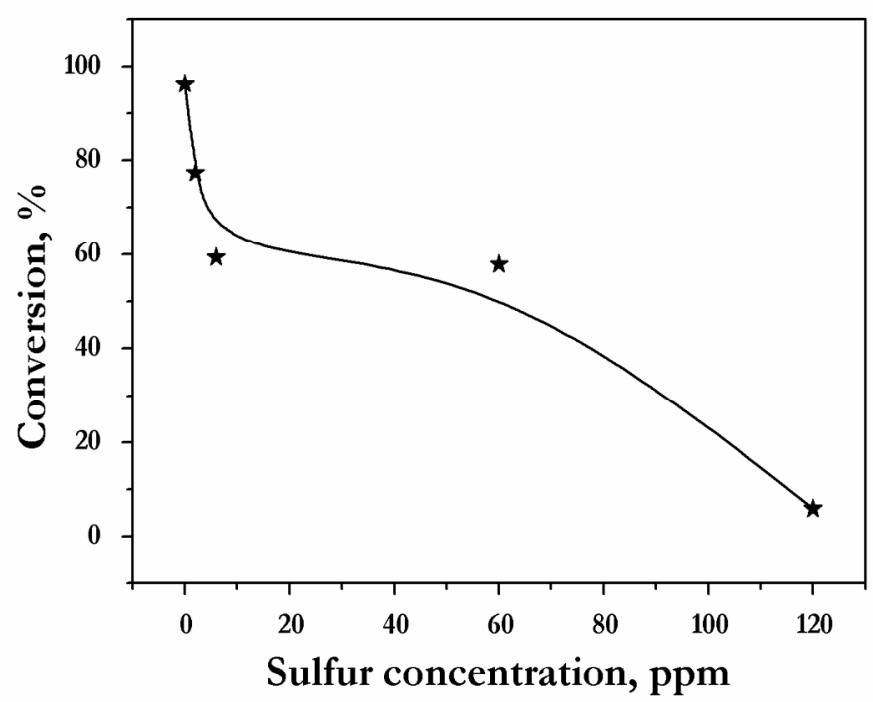

ACS Paragon Plus Environment 